\title{
INFRAESTRUTURA E INDICADORES DE ADESÃO À HIGIENE DAS MÃOS EM UNIDADE DE TERAPIA INTENSIVA
}

\section{INFRASTRUCTURE AND HAND HYGIENE COMPLIANCE INDICATORS IN AN INTENSIVE CARE UNIT}

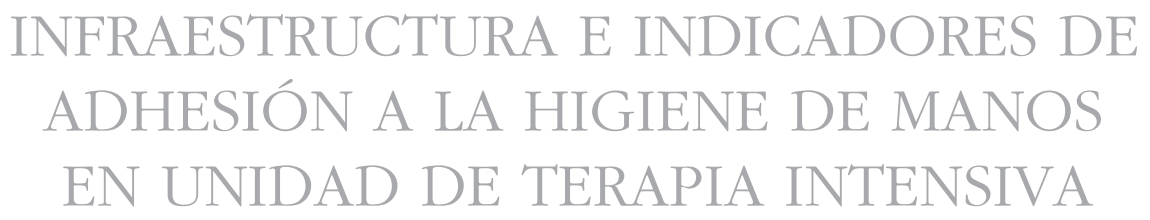

Alaíde Francisca de Castro ${ }^{1}$

Maria Cristina Soares Rodrigues ${ }^{2}$

Como citar este artigo: Castro AF, Rodrigues MCS. Infraestrutura e indicadores de adesão à higiene das mãos em unidade de terapia intensiva. Rev baiana enferm. 2018; 32:e26099.

Objetivo: avaliar a infraestrutura e medir indicadores de adesão à higiene das mãos em Unidade de Terapia Intensiva. Método: estudo de caso descritivo-exploratório, utilizando três instrumentos estruturados para registrar as características dos profissionais, a infraestrutura disponível e a adesão à higiene das mãos. Aplicado teste Quiquadrado. Resultados: as preparações alcoólicas eram insuficientes e as torneiras inadequadas. Foram monitoradas 516 oportunidades de observação e ocorreram 337 ações de higiene das mãos, obtendo-se média de adesão de 65,3\%, majoritariamente higiene simples. Existiu diferença da adesão entre os profissionais, com maior taxa dos médicos $(77,9 \%)$, seguida dos fisioterapeutas $(73,8 \%)$, enfermeiros $(72,1 \%)$ e técnicos de enfermagem $(57,7 \%)$. O momento anterior ao contato com o paciente e antes da realização de procedimentos assépticos apresentaram menor adesão. Evidenciada maior adesão durante a manhã, e sem diferença entre dias da semana. Conclusão: a infraestrutura insuficiente refletiu na baixa adesão à fricção antisséptica.

Descritores: Higiene das Mãos. Unidades de Terapia Intensiva. Avaliação em Saúde. Padrão de Cuidado. Segurança do Paciente.

Objective: assess infrastructure and measure hand hygiene compliance indicators in an intensive care unit. Method: descriptive, exploratory case study, using three structured instruments to record the characteristics of the professionals, infrastructure in the unit and hand hygiene compliance. A chi-square test was applied. Results: the alcohol-based handrub formulations were insufficient and the taps were inappropriate. A total of 516 hand hygiene opportunities were monitored and, of these, hands were washed 337 times, corresponding to a mean compliance of 65.3\%, mostly with routine washing. Compliance differed among professionals: physicians had the highest rate (77.9\%), followed by physical therapists (73.8\%), nurses (72.1\%) and nursing technicians (57.7\%). The moments prior to touching patients and before clean/aseptic procedures had the lowest compliance rate. There was greater compliance in the

\footnotetext{
Enfermeira. Mestre em Enfermagem. Chefe de Divisão de Enfermagem. Hospital Universitário de Brasília. Brasília, Distrito Federal, Brasil. castroalaide@gmail.com Enfermeira. Doutora em Ciências da Saúde. Pós-doutora. Docente Associado do Departamento de Enfermagem e do Programa de Pós-graduação em Enfermagem da Universidade de Brasília. Brasília, Distrito Federal, Brasil.
} 
morning shifts, and no differences were noted between the days of the week. Conclusion: insufficient infrastructure was reflected in low hand hygiene compliance.

Descriptors: Hand Hygiene. Intensive Care Units. Health Assessment. Care Standard. Patient Safety.

Objetivo: evaluar la infraestructura y medir indicadores de adhesión a la higiene de manos en Unidad de Terapia Intensiva. Método: estudio de caso descriptivo-exploratorio, utilizando tres elementos estructurados para registrar las características de los profesionales, la infraestructura disponible y la adhesión a la higiene de manos. Aplicado test Chi-cuadrado. Resultados: las preparaciones alcohólicas eran insuficientes; los grifos, inadecuados. Fueron monitoreadas 516 oportunidades de observación, ocurriendo 337 acciones de higiene de manos, obteniéndose promedio de adhesión de 65,3\%, mayoritariamente higienes simples. Existió diferencia de adhesión entreprofesionales, con mayor tasa en médicos (77,9\%), seguidos por los fisioterapeutas $(73,8 \%)$, enfermeros $(72,1 \%)$ y auxiliares de enfermería (57,7\%). El momento anterior al contacto con el paciente y antes de realizar procedimientos asépticos presentaron menores adbesiones. Evidenciada mayor adhesión durante la mañana, sin diferencia entre dias de la semana. Conclusión: la infraestructura insuficiente se reflejó en la baja adhesión a la higiene antiséptica.

Descriptores: Higiene de las Manos. Unidades de Cuidados Intensivos. Evaluación en Salud. Nivel de Atención. Seguridad del Paciente.

\section{Introdução}

As infecções relacionadas à assistência à saúde (IRAS) constituem um grande problema para a saúde pública, pois são eventos adversos que ameaçam a segurança dos pacientes. Atualmente, a estimativa é a cada 100 pacientes internados, pelo menos 10 em países em desenvolvimento e 7 em países desenvolvidos, irão adquirir IRAS $^{(1)}$. No Brasil e no Distrito Federal (DF), as taxas de IRAS nas Unidades de Terapia Intensiva (UTI) por microrganismos multirresistentes são muito altas e preocupantes ${ }^{(2-3)}$. As densidades de incidências de infecções da IRAS associadas ao uso de dispositivos invasivos variaram de 4,6 a 13,6 por mil dispositivos/dias nas UTIs do Brasil no ano de 2016. Já a resistência aos antimicrobianos identificada entre os microrganismos envolvidos nas infecções primárias de corrente sanguínea variou de 9,9 a $85,8 \%{ }^{(2)}$.

Entre as principais ações recomendadas pela Organização Mundial de Saúde (OMS) está o combate à resistência microbiana através da prevenção das IRAS e da transmissão cruzada de microrganismos no ambiente hospitalar, principalmente em áreas de cuidados com pacientes críticos como a Unidade de Terapia Intensiva $(\mathrm{UTI})^{(1)}$.

Como a melhoria da adesão às precauções padrão e em casos específicos às precauções especiais pelos profissionais de saúde são reconhecidamente a forma mais eficaz de sucesso para a redução das IRAS e transmissão cruzada de microrganismos, são necessários esforços dos gestores para promover adequações na infraestrutura e realizar análises detalhadas de indicadores que mensurem tais práticas ${ }^{(1-5)}$.

As precauções padrão são usadas nos cuidados com os pacientes, produtos, equipamentos e superfícies e englobam: higiene das mãos (HM) pelos profissionais de saúde; uso correto de equipamentos de proteção individuais; acomodação do paciente em local de acordo com o risco; higiene respiratória ou etiqueta de tosse; manuseio/coleta seguros de roupas, resíduos e perfurocortantes; práticas adequadas de limpeza e desinfecção com artigos, equipamentos e superfícies; e práticas seguras no manejo de injeções ${ }^{(4-5)}$.

Para realizar a HM são recomendadas quatro formas diferentes, quais sejam: higiene simples com água e sabonete líquido; fricção antisséptica com preparações alcoólicas, considerada padrão ouro; higiene antisséptica das mãos; e antissepsia cirúrgica das mãos. A escolha do tipo de HM a ser efetuado depende do grau de invasão do procedimento que será realizado no paciente e da presença ou não de sujidade nas 
mãos. As mãos, unhas e punhos não devem possuir adornos e as quatro diferentes técnicas envolvem a higiene completa de todas as partes das mãos e dedos ${ }^{(6)}$.

A estrutura física necessária em UTIs envolve distribuição de lavatórios para HM, com torneiras acionadas de forma a evitar o contato das mãos e providos de sabonete líquido, antisséptico e papel toalha. Todos os leitos devem dispor de preparações alcoólicas ao alcance das mãos do profissional, que podem ser acondicionados em dispensadores fixados nas paredes ou aos pés dos leitos ou em frascos móveis que podem ser colocados sobre carrinhos, bancadas ou no bolso. Treinamentos e lembretes sobre a importância da HM no local de trabalho, bem como orientações sobre técnicas e momentos indicados, são apontados como importantes estratégias de boas práticas ${ }^{(6)}$.

Apesar de evidências científicas sobre o impacto das boas práticas de HM na prevenção de IRAS, a adesão pelos profissionais de saúde ainda é baixa. A adesão à HM foi estudada em diferentes localidades do mundo, indicando que é menor que 40\%, e nos países em desenvolvimento, publicações apontam taxas de adesão à HM muito variáveis. Em alguns serviços, por exemplo, foi encontrada taxa muito baixa, chegando a $10 \%{ }^{(4-9)}$.

No Brasil, a Agência Nacional de Vigilância Sanitária (Anvisa) regulamenta o funcionamento de UTIs com uma equipe mínima para o cuidado que deve ser composta de um médico, um enfermeiro e um fisioterapeuta para cada $10 \mathrm{pa}-$ cientes, um técnico de enfermagem para cada dois pacientes e também um médico diarista nos períodos da manhã e tarde ${ }^{(10)}$.

Segundo dados da OMS, equipes treinadas em estabelecimentos de saúde com estrutura física e recursos adequados para a prática conseguem manter adesão maior que 60\%. Alguns serviços, principalmente em atendimento neonatal e pediátrico, podem alcançar taxas de adesão maiores que $80 \%{ }^{(6)}$. Pesquisa recente avalia e demonstra significativa redução nas taxas de infecção, quando equipes que já possuem altas taxas de adesão à HM conseguem aumentar mais essas taxas, chegando a aproximadamente $95 \%{ }^{(11)}$.

No contexto da segurança do paciente, a não realização de HM pelo profissional de saúde em procedimento assistencial é considerada uma violação. Violação é a divergência deliberada de um procedimento cirúrgico, um padrão ou regra, habitualmente intencional, apesar de raramente maliciosa, que pode tornar-se rotineira ou automática em determinado contexto ${ }^{(12)}$.

A Estratégia Multimodal da OMS para melhorar a adesão à HM tem sido amplamente implementada no mundo em diferentes formas e contextos, obtendo resultados muito variados. No entanto, um estudo aponta que as pesquisas ainda não conseguiram identificar qual a melhor metodologia para elevar e manter altas taxas de adesão à HM entre profissionais de saúde ${ }^{(13)}$. Vale ressaltar que o método de mensuração da adesão à HM proposto na estratégia da OMS refere-se à observação direta da prática assistencial realizada por profissionais treinados, usando-se um formulário especialmente desenvolvido para esse fim $^{(6,14)}$. Tal método é influenciado pelo efeito Hawthorne, que significa a mudança de atitude da pessoa, por saber que está sendo observada ${ }^{(14-15)}$.

Durante os cuidados assistenciais, existem indicações e oportunidades para a realização das ações de HM que surgem à medida que os procedimentos ocorrem. Com a intenção de melhorar o entendimento dos profissionais, são sintetizadas em cinco indicações: antes de tocar o paciente; antes de realizar procedimento limpo/ asséptico; após risco de exposição a fluidos corporais; após tocar o paciente; e após tocar superfícies próximas ao paciente ${ }^{(6,14)}$.

Em contextos de altas taxas de IRAS, que são considerados indicadores de resultados, faz-se necessário avaliar indicadores de estrutura e processo envolvidos, especialmente em hospitais universitários, lócus de treinamento inicial e continuado de estudantes, residentes e profissionais da saúde. Esta afirmação direciona as pesquisadoras à seguinte indagação: Qual é a estrutura disponível e a adesão às práticas de 
HM pelos profissionais na UTI de um hospital de ensino?

Diante dessa justificativa e questionamento de pesquisa, traçou-se como objetivo do estudo avaliar a infraestrutura e medir indicadores de adesão à higiene das mãos em Unidade de Terapia Intensiva.

\section{Método}

Estudo de caso descritivo e exploratório, com abordagem quantitativa, desenvolvido entre os meses de setembro e dezembro de 2015, em um hospital de ensino de grande porte localizado na cidade de Brasília, Distrito Federal, Brasil. Elegeu-se como cenário de investigação a UTI Adulto, com 18 leitos, dos quais somente 10 estavam ativos e destinados ao atendimento de pacientes agudos clínicos e cirúrgicos à época da realização da pesquisa. O local foi escolhido porque apresentava altas taxas de IRAS e frequente presença de pacientes colonizados e/ou infectados por microrganismos multirresistentes, como é comum em UTIs brasileiras.

A pesquisa foi realizada em quatro etapas: aproximação da equipe de pesquisa com o campo e aplicação do Termo de Consentimento Livre e Esclarecido (TCLE); aplicação do questionário para caracterização dos profissionais participantes do estudo; treinamento do observador; e checagens da infraestrutura e da adesão à HM.

Foram incluídos na pesquisa os profissionais de saúde do quadro de pessoal fixo da UTI, composto por 55 colaboradores que aceitaram o convite para participar do estudo, a saber: médico intensivista $(n=9 ; 16,3 \%)$, enfermeiro $(n=10$; $18,1 \%)$, fisioterapeuta $(n=5 ; 7,2 \%)$, técnico de enfermagem $(n=31 ; 58,1 \%)$. Excluíram-se os que estavam em licença médica, férias ou outros afastamentos no período da coleta de dados. Assim, três profissionais $(5,4 \%)$ foram excluídos.

Foram aplicados três instrumentos. O primeiro foi um questionário estruturado e autoaplicável para coleta das variáveis referentes aos participantes da pesquisa, aplicado pelo pesquisador principal aos profissionais da UTI após terem aceitado o convite para participar da pesquisa. Para o registro das observações diretas da prática da adesão à HM foi usado um formulário validado, tipo checklist, da Estratégia Multimodal para Melhoria da Higiene das Mãos da OMS, constante do "Guia para Implantação: Estratégia Multimodal da OMS para Melhoria da Higienização das Mãos”, da Organização Pan-Americana da Saúde e Anvisa ${ }^{(6,12)}$. Com o objetivo de reduzir o efeito Hawthorne (principal limitação do estudo), um auxiliar de pesquisa não conhecido pelos profissionais da unidade foi treinado para aplicar o formulário de adesão e o questionário de registro da estrutura.

Conforme orientações da OMS, as sessões de observação da adesão tiveram duração de 20 a 30 minutos cada uma, foram distribuídas entre os turnos da manhã $(n=15 ; 34,8 \%)$, tarde $(n=18$; $41,8 \%)$ e noite $(n=10 ; 23,2 \%)$ e ocorreram 3 a 4 vezes por semana durante os meses de outubro a dezembro de 2015. Para a coleta dos dados, o observador posicionava-se no centro da UTI e iniciava a sessão de observação não participante, porém sem ocultar sua presença. Dessa maneira, foram feitas as análises das práticas assistenciais de um profissional por vez, sendo escolhido de forma aleatória aquele que dava início a algum cuidado com paciente ou que começava uma ação de HM. Os nomes dos observados foram registrados no formulário para controle do número de observações. Dessa forma, os profissionais foram observados individualmente por três a cinco oportunidades para HM, com o intuito de possibilitar que o maior número de participantes pudesse estar representado, evitando-se, assim, os vieses de seleção de turnos e pessoas.

As observações dos procedimentos assistenciais foram realizadas de forma a identificar e registrar se ocorreu ou não a ação de HM pelo profissional, quando teve uma oportunidade de fazê-la, e se a realizou com a técnica correta. Uma oportunidade para a HM surge quando ocorre uma ou mais das cinco indicações ou cinco momentos, isto é, antes de tocar o paciente, antes de realizar procedimento limpo/asséptico, após risco de exposição a fluidos corporais, após tocar o paciente e após tocar superfícies próximas ao paciente. 
O número de oportunidades observado foi obtido por amostra de conveniência. Assim, as oportunidades que surgiram, puderam ser observadas dentro do período e horário estabelecidos para coleta de dados. A taxa de adesão foi calculada pela aplicação de fórmula, em que o numerador expressava o número de ações de HM realizadas com a técnica completa e o denominador o número de oportunidades para realizar a ação de HM observados, multiplicado por 100 .

As observações da infraestrutura, como disponibilidade de insumos e de pessoal, foram registradas em outro questionário estruturado, tipo checklist, construído e adaptado com base nos indicadores validados do "Manual de Avaliação da Qualidade de Práticas de Controle de Infecção Hospitalar"(16). Ao final de cada sessão de observação da adesão, o questionário de estrutura foi preenchido pelo observador.

A distribuição de lavatórios para HM, da parte que se encontrava em funcionamento, era composta por quatro pias nas laterais do posto de enfermagem, que ocupava o centro da unidade, duas cubas nas laterais da bancada de preparo de medicamentos, uma pia dentro do expurgo, uma pia dentro do quarto de isolamento e uma pia na área do banheiro do quarto do isolamento.

As torneiras das pias eram de acionamento por pressão, dispensando, assim, o contato das mãos; as torneiras das cubas eram de abertura e fechamento manuais. No total, havia nove pias e duas cubas, sendo esse número suficiente para atender as exigências de regulamentações nacionais. Todas as pias e cubas dispunham de dispensadores de sabonete líquido, do tipo que é reabastecido com refil descartável, e papel toalha, exceto uma. As duas cubas também dispunham de almotolias com antisséptico degermante de gluconato de clorexidina ${ }^{\circledR}$.

As preparações alcoólicas eram fornecidas na forma de gel em dispensadores afixados nas paredes, do tipo que é reabastecido com refil descartável, totalizando cinco dispensadores distribuídos na parte interna da unidade. Somente no leito de número três, o dispensador estava no ponto de assistência, fixado na parede lateral ao leito; os demais dispensadores da unidade estavam fixados em pilastras, distribuídos no trajeto entre os leitos e o posto de enfermagem, todos localizados a mais de dois metros de distância dos leitos.

Foi identificada uma placa contendo instruções sobre a técnica da higiene simples das mãos e um cartaz com frase de incentivo à adesão à HM. Em uma pilastra havia um folder com orientações sobre as precauções padrão e especiais. Quatro documentos institucionais com orientações sobre as precauções e as rotinas de vigilância epidemiológica para microrganismos multirresistentes estavam disponíveis para consulta na unidade, nas formas impressa e eletrônica.

Os dados foram lançados no programa EPIINFO versão 3.5.1 e no aplicativo Excel da empresa Microsoft versão n.7. Foram calculadas as frequências absolutas das respostas, aplicado o teste Qui-quadrado $\left(\chi^{2}\right)$ de independência quando pertinente. A correção de Yates foi necessária em algumas situações, devido ao pequeno número de observações, quando estratificados pelas quatro categorias profissionais e cinco indicações/momentos. Posteriormente, apresentou-se o nível descritivo (ou $p$-valor), sendo considerado significativo valor de $p<0,05$.

A pesquisa foi aprovada pelo Comitê de Ética em Pesquisa com Seres Humanos da Faculdade de Ciências da Saúde da Universidade de Brasília, sob o Parecer n. 1.188.047/2015. Aos participantes requisitou-se anuência, por meio do preenchimento do TCLE, e foram garantidos sigilo e anonimato.

\section{Resultados}

Participaram da pesquisa 52 profissionais, representados por $29(55,7 \%)$ técnicos de enfermagem, 10 enfermeiros (19,2\%), 9 médicos $(17,3 \%)$ e 4 fisioterapeutas (7,7\%). Predominaram pessoas do sexo feminino $(n=34 ; 65,3 \%)$, na faixa etária entre 30 e 40 anos ( $n=29 ; 55,7 \%)$, com tempo de atuação na profissão de 6 a 10 anos $(n=19 ; 36,5 \%)$ e com jornada de trabalho até 40 horas semanais $(n=31 ; 59,6 \%)$. 
Entre as quatro categorias profissionais avaliadas, a maioria dos participantes ( $\mathrm{n}=50 ; 96,1 \%)$ afirmou ter recebido capacitação sobre HM durante a formação profissional. Quanto ao treinamento em serviço, somente quatro médicos $(44,4 \%)$ informaram ter recebido; entre as demais categorias, a maioria $(n=40 ; 93,0 \%)$ afirmou ter recebido. As análises estatísticas não indicaram diferença significativa $\left(\chi^{2} 0,097, p=0,99\right)$.

A disponibilidade de produtos para HM foi avaliada em 36 sessões de observação. Identificou-se que o abastecimento de sabonete líquido e preparações alcoólicas era irregular; na maioria das sessões ( $n=24 ; 66,6 \%$ ), havia um dispensador de sabonete líquido vazio e um dispensador de preparação alcoólica desabastecido $(n=27$; 75,0\%).

Também foi constatado uso elevado de adornos entre todas as categorias assistenciais das equipes da UTI. Somente em quatro sessões $(11,1 \%)$ observou-se que nenhum profissional estava com adornos nas mãos.
Quanto à quantidade de recursos humanos por categoria profissional, identificou-se ausência de médicos diaristas na totalidade (100\%) e ausência de fisioterapeuta em uma única sessão de observação (2,7\%). Na maioria das sessões, entretanto, foi identificado maior número de profissionais que o mínimo necessário, assim distribuído: enfermeiros, em 13 sessões (36,1\%); fisioterapeutas, em 12 sessões (33,3\%); e técnicos de enfermagem, em 32 sessões $(88,8 \%)$.

Foram monitoradas 516 oportunidades de HM e ocorreram 337 ações de HM, o que representa adesão média de $65,3 \%$. Os resultados obtidos são mostrados na Tabela 1 . Obteve-se $p<0,01$ em duas situações e é possível afirmar que existiu dependência entre a taxa de adesão e as indicações (cinco momentos) de HM e em relação às categorias profissionais. Entretanto, com relação aos dias da semana e ao turno de serviço, a diferença não foi significativa.

Tabela 1 - Taxa de adesão à higiene das mãos dos profissionais que atuam na assistência direta aos pacientes, na Unidade de Terapia Intensiva do hospital de ensino. Brasília, Distrito Federal, Brasil - $2015(\mathrm{~N}=52)$

(continua)

\begin{tabular}{|c|c|c|c|c|}
\hline Variáveis & $\begin{array}{c}\text { Número de } \\
\text { oportunidades } \\
\text { (n) }\end{array}$ & $\begin{array}{l}\text { Número de } \\
\text { higiene das } \\
\text { mãos } \\
\text { (n) }\end{array}$ & $\begin{array}{c}\text { Taxa de } \\
\text { adesão à } \\
\text { higiene } \\
\text { das mãos } \\
\text { (\%) }\end{array}$ & $P$-valor \\
\hline \multicolumn{5}{|l|}{ Indicações/oportunidades/ cinco momentos } \\
\hline Antes de tocar o paciente & 117 & 47 & 40.1 & \multirow{5}{*}{$<0.0001$} \\
\hline $\begin{array}{l}\text { Antes de realizar procedimento limpo/ } \\
\text { asséptico }\end{array}$ & 77 & 22 & 28.5 & \\
\hline Após risco de exposição a fluidos corporais & 148 & 129 & 87.1 & \\
\hline Após tocar o paciente & 136 & 114 & 83.8 & \\
\hline Após tocar superfícies próximas ao paciente & 73 & 48 & 65.7 & \\
\hline \multicolumn{5}{|l|}{ Categoria profissional } \\
\hline Técnico de enfermagem & 279 & 161 & 57.7 & \multirow{4}{*}{0.001} \\
\hline Enfermeiro & 104 & 75 & 72.1 & \\
\hline Médico & 68 & 53 & 77.9 & \\
\hline Fisioterapeuta & 65 & 48 & 73.8 & \\
\hline \multicolumn{5}{|l|}{ Dias da semana } \\
\hline Segunda-feira & 103 & 65 & 63.1 & \multirow{4}{*}{0.28} \\
\hline Terça-feira & 73 & 42 & 57.5 & \\
\hline Quinta-feira & 225 & 156 & 69.3 & \\
\hline Sexta-feira & 115 & 74 & 64.3 & \\
\hline
\end{tabular}


Tabela 1 - Taxa de adesão à higiene das mãos dos profissionais que atuam na assistência direta aos pacientes, na Unidade de Terapia Intensiva do hospital de ensino. Brasília, Distrito Federal, Brasil - $2015(\mathrm{~N}=52)$

(conclusão)

\begin{tabular}{|c|c|c|c|c|}
\hline Variáveis & $\begin{array}{c}\text { Número de } \\
\text { oportunidades } \\
\text { (n) }\end{array}$ & $\begin{array}{l}\text { Número de } \\
\text { higiene das } \\
\text { mãos } \\
\text { (n) }\end{array}$ & $\begin{array}{c}\text { Taxa de } \\
\text { adesão à } \\
\text { higiene } \\
\text { das mãos } \\
(\%)\end{array}$ & $P$-valor \\
\hline \multicolumn{5}{|l|}{ Turno } \\
\hline Manhã & 187 & 133 & 71.1 & \multirow{4}{*}{0.10} \\
\hline Tarde & 209 & 128 & 61.2 & \\
\hline Noite & 120 & 76 & 63.3 & \\
\hline Total & 516 & 337 & 65.3 & \\
\hline
\end{tabular}

Fonte: Elaboração própria.

Como a adesão por categoria profissional possui taxas variadas e significativas para $\alpha=1 \%$ e por turnos de trabalho não apresentou significância, optou-se por analisar a adesão de cada categoria profissional em cada turno de trabalho separadamente. A adesão dos técnicos de enfermagem variou significativamente entre os turnos da manhã $(72,2 \%)$, tarde $(50,4 \%)$ e noite $(45,5 \%)$. Entre os enfermeiros, também ocorreu variação significativa, com a adesão no período da manhã de $75 \%$, tarde $61,1 \%$ e noite $92,3 \%$. A adesão dos médicos variou de $67,6 \%$, encontrada no período da manhã, a $90 \%$ à tarde e $85,1 \%$ à noite. Os fisioterapeutas apresentaram adesão de 66,6\% durante a manhã, 78,1\% à tarde e 75\% à noite. Verificou-se correlação significativa com $p<0,01$ para os turnos da tarde $(p=0,003)$ e noite $(\mathrm{p}=0,0003)$, devido à muito baixa adesão dos técnicos de enfermagem nesses turnos.

Para aumentar a sensibilidade e complementar as análises, foram avaliados os turnos de trabalho individualmente, por categorias profissionais. Nesse caso, pode-se afirmar que existiu dependência $(\mathrm{p}<0,05)$ entre os enfermeiros e os turnos de trabalho, com maior adesão entre os enfermeiros do noturno $(92,3 \%)$

\section{Discussão}

As informações referentes às características da equipe multiprofissional estudada, com relação à idade, mais da metade $(55,7 \%)$ dos profissionais encontra-se na faixa etária de 30 a 40 anos, mais de um terço (36,5\%) com tempo de experiência na profissão entre 6 e 10 anos, profissionais que atuam em sua maioria em somente um ou dois vínculos empregatícios (59,6\% afirmaram trabalhar somente até 40 horas semanais) e conhecimento sobre precauções $(96,1 \%$ receberam capacitações e 93,0\% receberam treinamentos), são positivas para favorecer melhor desempenho no que se refere à adesão à $\mathrm{HM}^{(6,14)}$.

Quanto à estrutura física, o número e a distribuição dos lavatórios para HM estavam em conformidade com as boas práticas. Entretanto, as torneiras das cubas disponíveis na UTI avaliada não atendiam à exigência de serem acionadas de forma a evitar o contato das mãos.

Uma das cinco regras de ouro da HM é que ela deve ser feita no ponto de assistência, compreendido como o local onde se encontram o paciente e o profissional, e o cuidado está se realizando. Para tanto, todos os leitos devem dispor de preparações alcoólicas ao alcance das mãos do profissional. Quanto à localização e quantidade inadequadas de dispensadores de preparações alcóolicas constatada, tem-se a apontar que, em UTIs com estrutura de separação de leitos por cortinas, outras apresentações de preparações alcoólicas são indicadas, como em frascos móveis que podem ser colocados sobre carrinhos, bancadas ou no bolso ou, ainda, fixados aos pés dos leitos ${ }^{(6,14)}$. 
A padronização de rotinas sistemáticas de abastecimento dos dispositivos também é necessária, para que não ocorram desabastecimentos. Problemas estruturais relacionados à quantidade e qualidade dos lavatórios e produtos para a HM são frequentemente citados na literatura como relacionados à baixa adesão à prática de $\mathrm{HM}^{(6,8,14)}$.

Lembretes sobre a importância da HM no local de trabalho, bem como orientações sobre técnicas e momentos indicados, são apontados como importantes para estratégias de melhorias $^{(6,14)}$. Na unidade estudada, essas sinalizações apresentavam-se insuficientes. Áreas críticas, como UTI, não devem possuir papéis fixados em paredes ou cartazes, pois não são passíveis de limpeza. Para essas áreas, recomenda-se que as sinalizações sejam feitas com materiais que possibilitem limpeza, por exemplo, placas em acrílico ou plástico.

A qualidade da técnica de HM é comprometida quando existe a presença de adornos, como anéis, pulseiras, relógios ou unhas artificiais nas mãos ${ }^{(6,14)}$. Não há como realizar higiene correta das mãos com o uso de adornos. Na UTI em avaliação, verificou-se, na maioria das sessões de observação, que existiam profissionais de saúde de todas as categorias com algum tipo de adorno nas mãos, sendo mais comumente encontradas alianças e anéis. No presente estudo, durante a avaliação da adesão à HM, considerou-se como oportunidade de observação quando o profissional efetuou a técnica completa de higiene, porém a presença de adorno nas mãos dos profissionais comprometeu a qualidade de todas as ações de HM realizadas.

Quanto à avaliação da quantidade de recursos humanos, a principal inadequação identificada foi a falta de médico diarista/rotineiro. Contrariamente, ocorreu a presença de maior número de profissionais enfermeiros e de técnicos de enfermagem. Entre os fisioterapeutas, a distribuição dos profissionais nos turnos e dias de trabalho não foi proporcional ao número de leitos ocupados, o que levou à diferença de uma sessão de observação. A redistribuição dos profissionais nas escalas de trabalho deve ser realizada priorizando-se a necessidade do serviço. A carência de recursos humanos em quantidade e qualificação adequadas é apontada como um dos principais limitadores da adesão às boas práticas e protocolos de cuidados específicos ${ }^{(4-6,14)}$.

A taxa de adesão de HM verificada por observação direta encontrada na unidade foi maior do que em outros três estudos nacionais que identificaram adesão de $26,5 \%$ e $43,7 \%{ }^{(8-9,17)}$. Essa taxa de adesão é maior que a média geral encontrada em demais áreas hospitalares, e é compatível ou menor do que taxas encontradas em outros estudos que avaliaram a adesão à HM em UTI, ao lidar com pacientes que estavam com e sem precauções de contato $^{(11,18-19)}$.

Os achados relativos às diferenças de adesão entre as categorias profissionais, permitiram identificar-se a maior taxa de adesão dos médicos, seguida dos fisioterapeutas, enfermeiros e menor dos técnicos de enfermagem, diferem da maioria dos outros estudos realizados em UTI, que identificaram menores taxas de adesão entre médicos $^{(7,18-21)}$. No entanto, no Brasil, outro estudo também encontrou maior taxa de adesão entre os médicos e entre equipes de auxiliares de enfermagem e menor taxa de adesão entre os fisioterapeutas ${ }^{(8)}$. Um estudo nacional mais recente encontrou taxa de adesão à HM muito baixa, com média de 43,7\%, mas com a maior adesão entre os fisioterapeutas e menor entre os técnicos de enfermagem ${ }^{(17)}$. A menor taxa de adesão encontrada nos turnos da tarde e noite também pôde ser verificada em outros estudos $^{(17,20)}$.

Quanto ao tipo de HM realizada pelos profissionais na UTI do hospital de ensino, esta foi predominantemente feita com água e sabonete, semelhantemente a dados de pesquisas encontrados em outras UTIs do Brasil ${ }^{(8,17)}$.

A higiene simples das mãos com água e sabonete ou higiene antisséptica das mãos com água e antisséptico degermante foram os tipos de HM que predominaram na prática assistencial até o ano de 2002, quando foram publicados dados indicando a superioridade das preparações alcoólicas para a HM. Posteriormente, em 2005, 
com o lançamento da Estratégia Multimodal da OMS, que prioriza a HM na assistência à saúde com as preparações alcoólicas, o uso desses produtos começou a ser incorporado nos serviços de saúde do Brasil. Somente no ano de 2010, a Anvisa tornou obrigatório o uso das preparações alcoólicas para a HM nos hospitais.

A maior experiência e o comportamento habitual do uso de água e sabonete para higienizar as mãos pode ser uma das razões da preferência dos profissionais de saúde para usarem a técnica da higiene simples. Um segundo motivo apontado foi o tipo de luvas de procedimentos utilizado no serviço de saúde em estudo, que eram de látex e possuíam pequena quantidade de talco. A presença de talco nas mãos, após a remoção das luvas, não possibilita o uso da preparação alcoólica e faz com que o profissional precise usar a água para higienizá-las. Também os antissépticos deveriam estar disponíveis nas pias, já que a maioria dos pacientes da unidade estavam em precaução de contato.

Outro motivo para a baixa adesão ao uso das preparações alcoólicas é a pouca disponibilidade desses produtos na unidade. Além de estarem disponíveis em dispensadores fixos de parede, em geral fora do ponto de assistência, esses também estavam localizados próximos às pias e muitas vezes encontravam-se desabastecidos.

Os dois primeiros momentos para HM (antes de tocar o paciente e antes de realizar procedimentos limpos/assépticos) estão diretamente ligados à proteção do paciente contra as IRAS e os demais três momentos são ligados à proteção dos profissionais e/ou a redução da contaminação do ambiente. Na UTI estudada, os dois primeiros momentos tiveram significativas menores taxas de adesão quando comparados aos demais, o que sugere que os profissionais tiveram maior comprometimento com a própria segurança.

A avaliação de processos de trabalho com observações diretas apresenta vantagens e desvantagens, sendo discutida na literatura por diferentes autores e instituições ${ }^{(6-8,11-15)}$. O efeito Hawthorne, que significa a mudança de atitude da pessoa por saber que está sendo observada, é a limitação mais reconhecida do método de observação direta. No entanto, buscou-se minimizá-lo com a participação de auxiliar de pesquisa treinada e não vinculada à instituição. As limitações foram superadas, porque se utilizou método padronizado e uniforme para a coleta de dados, além de evitar-se vieses de seleção de turno ou pessoas, pois foram realizadas observações em todos os turnos da jornada de trabalho e distribuição do número de observações entre os participantes.

Portanto, esta pesquisa resulta em importantes contribuições para o campo da enfermagem e em vigilância em saúde, visto que permitiu chegar a conclusões particulares da unidade em avaliação, que mostram limitada infraestrutura para adesão à HM pelos profissionais. Por conseguinte, a pesquisa oferece mais aporte de conhecimentos sobre o tema investigado no meio científico da área em nosso país. Adicionalmente, como produto para o desenvolvimento do estudo, produziu-se um instrumento que pode ser usado como ferramenta auxiliar em monitoramentos observacionais de disponibilidade de insumos e uso de EPIs em hospitais brasileiros.

Uma importante reflexão convergente ao pensamento de pesquisadores sobre a atual pauta de estudos e discussões acerca da segurança do paciente e promoção da saúde, é que a cultura e o clima de segurança devem fazer parte dos ambientes de cuidados prestados, para que proporcionem condições seguras para planejar ações de melhoria contínua com adequada infraestrutura física, de recursos humanos, de materiais e equipamentos para o desenvolvimento seguro de ações em saúde ${ }^{(23)}$. Nesse entendimento, a alta gestão do hospital de ensino em foco, tendo como premissa o envolvimento e engajamento de gestores e profissionais da assistência da unidade investigada, necessita direcionar ações que possibilitem proporcionar um cuidado mais seguro e de alta qualidade, tais como: medidas educativas, treinamento, além da imprescindível melhoria da infraestrutura. 


\section{Conclusão}

Ao avaliar idade, tempo de atuação na profissão, carga horária semanal de trabalho e participação em capacitações e treinamentos, identificou-se que o conjunto de informações reunidas sobre as características da equipe multiprofissional da UTI do hospital de ensino do DF são positivas para favorecer melhor desempenho na adesão à HM. Entretanto, foram identificadas limitações de recursos humanos, como ausência de médico diarista, e da estrutura física, como torneiras de acionamento manual nos lavatórios, e dos produtos disponíveis para a execução das práticas de HM, que não eram adequados ou suficientes, bem como a não disponibilidade de preparações alcóolicas ao alcance das mãos nos leitos.

A média da adesão à higiene das mãos foi de 65,3\%, principalmente realizada com a técnica da higiene simples. Existiu diferença estatisticamente significativa de adesão entre as categorias profissionais, isto é, houve maior taxa de adesão entre os médicos, seguido dos fisioterapeutas, enfermeiros, e a menor taxa foi observada entre os técnicos de enfermagem. Apesar de ter sido evidenciada significância estatística na taxa de adesão dos técnicos de enfermagem nos períodos da tarde e noite, não houve diferença significativa entre os dias da semana. Os momentos antes de tocar o paciente e antes de realizar procedimentos limpos/assépticos apresentaram menor adesão.

O contexto das inadequações da estrutura física e dos recursos humanos, e a insuficiência de insumos pode ter influenciado na baixa adesão à fricção antisséptica com preparações alcoólicas, considerada padrão ouro, embora a técnica de observação direta na coleta de dados possa ser um limitador do estudo devido ao efeito Hawthorne. No entanto, os resultados obtidos mostram cenário, comportamentos e práticas dos profissionais que expressam relevantes indicadores de estrutura e processo na unidade estudada, considerando-se a importância do contínuo desafio de se aumentar a adesão à HM para reduzir as IRAS e a transmissão cruzada de microrganismos, especialmente em unidades de cuidados de pacientes críticos.

\section{Colaborações:}

1. concepção, projeto, análise e interpretação dos dados: Alaíde Francisca de Castro e Maria Cristina Soares Rodrigues;

2. redação do artigo e revisão crítica relevante do conteúdo intelectual: Alaíde Francisca de Castro e Maria Cristina Soares Rodrigues;

3. aprovação final da versão a ser publicada: Alaíde Francisca de Castro e Maria Cristina Soares Rodrigues.

\section{Referências}

1. World Health Organization. Report on the burden of endemic health care associated infection worldwide. A systematic review of the literature [Internet]. Geneva; 2011 [cited 2014 Aug 24]. Available from: http:// apps.who.int/iris/bitstream/handle/10665/80135/ 9789241501507 _eng.pdf; jsessionid= C 2 D 651 E 2 D 7 F 4 A 2 D 16 B B B 853 F E 58 F1B7A?sequence $=1$

2. Brasil. Agência Nacional de Vigilância Sanitária. Boletim Segurança do Paciente e Qualidade em Serviços de Saúde no 16: Avaliação dos indicadores nacionais das Infecções Relacionadas à Assistência à Saúde (IRAS) e Resistência microbiana do ano de 2016 [Internet]. Brasília; 2017 [cited 2017 Aug 24]. Available from: http://www20.anvisa.gov.br/ segurancadopaciente/index.php/publicacoes/ category/boletins-estatisticos

3. Distrito Federal. Secretaria de Saúde do Distrito Federal. Plano de enfrentamento da resistência bacteriana nas áreas críticas dos hospitais públicos do GDF 2015. Brasília; 2015.

4. Yokoe DS, Anderson DJ, Berenholtz SM, Calfee DP, Dubberke ER, Ellingson KD, et al. A compendium of strategies to prevent healthcareassociated infections in acute care hospitals: 2014 Updates. Infect Control Hosp Epidemiol [Internet]. 2014 [cited 2017 Aug 16];35(8):967-77. Available 
from: https://www.ncbi.nlm.nih.gov/pmc/articles/ PMC4223864/

5. Tacconelli E, Cataldo MA, Dancer SJ, Angelis GD, Falcone M, Frank U, et al. ESCMID guidelines for the management of the infection control measures to reduce transmission of multidrug-resistant Gram-negative bacteria in hospitalized patients. Clin Microbiol Infect [Internet]. 2014 [cited 2017 Jan 24];20(Suppl. 1):1-55. Available from: https:// doi.org/10.1111/1469-0691.12427

6. World Health Organization. WHO guidelines on hand hygiene in health care. First Global Patient Safety Challenge Clean Care is Safer Care. Geneva; 2009 [cited 2015 Jan 8]. Available from: http:// www.who.int/gpsc/5may/tools/9789241597906/ en/

7. Rosenthal VD, Pawar M, Leblebicioglu H, Navoa-Ng JA, Villamil-Gómez W, Armas-Ruiz A, et al. Impact of the International Nosocomial Infection Control Consortium (INICC) multidimensional hand hygiene approach over 13 years in 51 cities of 19 limited-resource countries from Latin America, Asia, the Middle East, and Europe. Infect Control Hosp Epidemiol [Internet]. 2013 [cited 2016 Feb 14];34(4):415-23. Available from: http://doi. org/10.1086/669860

8. Bathke J, Cunico PDA, Maziero ECS, Cauduro FLF, Sarquis LMM, Cruz EDDA. Infrastructure and adherence to hand hygiene: challenges to patient safety. Rev Gaúcha Enferm [Internet]. 2013 [cited 2017 Jun 19];34(2):78-85. Available from: http:// dx.doi.org/10.1590/S1983-14472013000200010

9. Trannin KPP, Campanharo CRV, Lopes MCBT, Okuno MFP, Batista REA. Adherence to hand hygiene: intervention and assessment. Cogitare Enferm [Internet]. 2016 [cited 2017 Jan 19];21(2):1-7. Available from: http://revistas.ufpr.br/cogitare/ article/view/44246/28016

10. Brasil. Agência Nacional de Vigilância Sanitária. Resolução RDC $\mathrm{n}^{\mathrm{o}}$ 7, de 24 de fevereiro de 2010. Dispõe sobre os requisitos mínimos para funcionamento de Unidade de Terapia Intensiva e dá outras providências. Brasília; 2010 [cited 2015 Feb 7]. Available from: https://www20.anvisa.gov. $\mathrm{br} /$ segurancadopaciente/index.php/legislacao/ item/rdc-7-de-24-de-fevereiro-de-2010

11. Sickbert-Bennett EE, DiBiase LM, Willis TMS, Wolak ES, Weber DJ, Rutala WA. Reduction of healthcare-associated infections by exceeding high compliance with hand hygiene practices. Emerg Infect Dis [Internet]. 2016 [cited 2018 Mar
26];22(9):1628-30. Available from: http://dx.doi. org/10.3201/eid2209.151440

12. Mendes W. Taxonomia em segurança do paciente. In: Souza P, Mendes W, organizadores. Segurança do paciente: conhecendo os riscos nas organizações de saúde. Rio de Janeiro: EAD/ENSP; 2014. p. 57-71.

13. Gould D, Moralejo D, Drey N, Chudleigh J, Taljaard M. Interventions to improve hand hygiene compliance in patient care: Reflections on three systematic reviews for the Cochrane Collaboration 2007-2017. J Infect Prev [Internet]. 2018 May [cited 2018 Mar 26];19(3):108-13. Available from: http://journals.sagepub.com/doi/ pdf/10.1177/1757177417751285

14. Organização Mundial da Saúde. Organização Pan-Americana da Saúde. Agência Nacional de Vigilância Sanitária. Guia para implementação: um Guia para a implantação da estratégia multimodal da OMS para melhoria da higienização das mãos. Brasília; 2008.

15. Hagel S, Reischke J, Kesselmeier M, Winning J, Gastmeier P, Brunkhorst FM, et al. Quantifying the Hawthorne effect in hand hygiene compliance through comparing direct observation with automated hand hygiene monitoring. Infect Control Hosp Epidemiol [Internet]. 2015 [cited 2018 Mar 26];36(8):957-62. Available from: DOI: 10.1017/ice.2015.93

16. São Paulo. Secretaria Estadual da Saúde. Divisão de Infecção Hospitalar. Centro de Vigilância Epidemiológica. Manual de avaliação da qualidade de práticas de controle de infecção hospitalar. São Paulo; 2006 [cited 2014 Mar 28]. Available from: http://www.cve.saude.sp.gov.br/htm/ih/ IH_MANUALFAPESP06.pdf

17. Souza LM, Ramos MF, Becker ESS, Meirelles LCS, Monteiro SAO. Adherence to the five moments for hand hygiene among intensive care professionals. Rev Gaúcha Enferm [Internet]. 2015 [cited 2016 Feb 3];36(4):21-8. Available from: http://dx.doi. org/10.1590/1983-1447.2015.04.49090

18. Leyva AM, Flores LM, Torres AGM, Caballero AGS, Amaro JAV, Gonzalez EG, et al. Hand hygiene compliance in patients under contact precautions and in the general hospital population. Am J Infect Control [Internet]. 2013 [cited 2016 Jul 25];41(11):976-8. Available from: https://doi. org/10.1016/j.ajic.2013.05.003 
19. Franca SR, Marra AR, Figueiredo RAO, Santos OFP, Teodoro JC, Edmond MB. The effect of contact precautions on hand hygiene compliance. Am J Infect Control [Internet]. 2013 [cited 2016 Dec 13];41(6):558-9. Available from: http://dx.doi. org/10.1016/j.ajic.2012.08.010

20. Alsubaie S, Maither A, Alalmaei W, Al-Shammari AD, Tashkandi M, Somily AM, et al. Determinants of hand hygiene noncompliance in intensive care units. Am J Infect Control [Internet]. 2013 [cited 2016 Aug 3];41(2):131-5. Available from: http:// dx.doi.org/10.1016/j.ajic.2012.02.035

21. Mahfouz AA, El Gamal M, Al-Azraqui TA. Hand hygiene non-compliance among intensive care unit health care workers in Aseer Central Hospital, south-western Saudi Arabia. Int J Infect Dis [Internet]. 2013 [cited 2016 Apr 19];17(9):e729-32. Available from: http://dx.doi.org/10.1016/ j.ijid.2013.02.025
22. Salama mf, Jamal WY, Mousa HA, Al-Abdulghani KA, Rotimi VO. The effect of hand hygiene compliance on hospital-acquired infections in an ICU setting in a Kuwaiti teaching hospital. J Infect Public Health [Internet]. 2013 [cited 2016 Nov 24];6(10):27-34. Available from: http://dx.doi. org/10.1016/j.jiph.2012.09.014

23. Pereira FGF, Matias EO, Caetano JA, Lima FET. Segurança do paciente e promoção da saúde: uma reflexão emergente. Rev baiana enferm [Internet]. 2015 [cited 2018 Mar 24];29(3):271-7. Available from: DOI: http://dx.doi.org/10.18471/ rbe.v29i3.12205

Recebido: 30 de março de 2018 Aprovado: 30 de setembro de 2018

Publicado: 4 de dezembro de 2018

A Revista Baiana de Enfermagem utiliza a Licença Creative Commons - Atribuição-NãoComercial 4.0 Internacional. https://creativecommons.org/licenses/by-nc/4.0/

Este artigo é de acesso aberto distribuído sob os termos da Licença Creative Commons (CC BY-NC). Esta licença permite que outros remixem, adaptem e criem a partir do seu trabalho para fins não comerciais. Embora os novos trabalhos tenham de lhe atribuir o devido crédito e não possam ser usados para fins comerciais, os usuários não têm de licenciar esses trabalhos derivados sob os mesmos termos. 